\title{
Teachers and their Educational Leadership in Organizational Change and Development: An Eritrean Case Study
}

\author{
Ravinder Rena ${ }^{1 *}$ and Berhane Aradom Tedla ${ }^{2}$ \\ 'NWU School of Business and Governance, North-West University, Mahikeng Campus, \\ Republic of South Africa; \\ ravinder.rena@nwu.ac.za \\ 2Department of Educational Administration, Faculty of Education, Eritrea Institute of Technology, \\ Mai-Nefhi, Eritrea; \\ berahen@yahoo.com
}

\begin{abstract}
Purpose and Objectives: The main purpose and objective of the study was to examine the teachers and educational leadership in organizational change in Eritrean context. It further explores and makes understanding the teacher leadership in relation to school effectiveness and improvement. The paper also identifies and investigates the current situation and inherent issues regarding teacher leadership in Eritrea. Methods: This research study was based on a positivist approach as the philosophy of the study. Using qualitative method in collecting and analysing the data, from different schools in the Central Region of Eritrea. The researchers employed an open-ended questionnaire and a focus group discussion to gather data, and thereby explore the condition, nature, and importance of teacher leadership. In doing so, the researchers selected 97 teachers randomly from a total of 150 teachers to complete open-ended questionnaires. Findings: This research study confirms the existence of a relationship between teachers' leadership and the top management at the Department of Education has been strained over a period of time. The ground level is not yet prepared or well-organized to treat teachers as leaders. The participants reported that teachers are primarily restricted merely to the role of information transmission without participating in curriculum development and roles of greater responsibility outside of the classroom environment. The findings further revealed that the Government plays a dominant role in school leadership and decision making process at all levels that eventually demotivates teachers' leadership. Application/Improvements: The research findings entail that it is important the Government of Eritrea makes an effort to develop a transparent and pro-active teacher leadership policy which can motivate and retain some of the committed teacher leaders who have the ability and enthusiasm to make a positive contribution in the educational development of the country. The study therefore provides some policy implications for the effective and efficient leadership management in education sector development.
\end{abstract}

Keywords: Educational Leadership, Educational Reform Policy, Eritrea, Organizational Change Development, Teacher Leadership Development

\section{Introduction and Background}

Eritrea, as many other countries, has seen a rising num- ber of challenges, especially in the provision of quality education. Perhaps the most challenging dilemma for

${ }^{*}$ Author for correspondence 
the Eritrean education system is the issue of leadership. A generation ago teachers in Eritrea were expected to be punctual, loyal and to teach, but today, with the massive influence of technological advancements and the global arena, teachers' roles have been expanded rapidly. They are expected to be leaders within their schools.

A teacher is termed as a curriculum leader and devoted talent helping to stimulate implementation of curricular change ${ }^{1}$. When leadership is shared or distributed, teachers become part of the entire system and play a significant role in putting the newly introduced changes into practice. In other words, teacher leadership causes teachers to utilize their individual and collective potential towards effective curriculum implementation.

In Eritrea, as elsewhere, the concept of teacher leadership is not yet fully understood, but its importance has become more vital in recent years. In 2005, the Ministry of Education introduced a new curriculum called 'Student Centered and Interactive Pedagogy, but the question still remains as to how teachers and principals will work collaboratively to implement it. With the curriculum reform, the leadership roles should have also been transferred from a centralized capacity (the role of one person) to the function of many teachers (decentralized) within the learning community. The long-standing belief in the power of one person is being challenged through ideas about shared leadership, committees, and distributed leadership ${ }^{2}$. However, the Ministry of Education introduced the new curriculum without modifying any of its ground policies concerning leadership and initiative. Thus the new curriculum has been very difficult to put into practice since without the efforts and passion of teachers the new concepts are lost somewhere between a school's administration and its students.
Leading an educational institution anywhere on the globe is a daunting issue. It requires the involvement of all stakeholders to guide, to motivate, and to inspire in order to build a nation of high-caliber education. More than ever, the $21^{\text {st }}$ century is a millennium of rapidly changing educational cultures. Schools experience a test of time to cope with the ever shifting world, and therefore education practices need to be constantly rethought and reformed. Failure to keep up with time's changes will result in poor school performance, which is why the presence of teachers willing and who are given the opportunity to take initiative in and out of the classroom are so important.

The purpose of the study is directed towards exploring and understanding teacher leadership in relation to school effectiveness and improvement. Firstly, it will identify and investigate the current situation and inherent issues regarding teacher leadership in Eritrea. Secondly, it will provide a platform for discussion on the issues of teacher leadership and school effectiveness. Thirdly, it will set the tone for further research on teacher leadership in the context of the Eritrean education system.

Literature reviews of the 1970's and 1980's are shown to be primarily focused on the importance of strong principal leadership rather than teacher leadership ${ }^{47}$, a situation still common to Eritrea. This implies that although schools had begun the process of democratization, teacher leadership was still limited and had not yet evolved into formal practice. Teachers were considered impediments rather than leaders of school improvement ${ }^{3,4}$. Even nowadays, teachers in Eritrea are the victims of imposed duties and considered the real cause of educational problems, failures of curriculum implementation, student disciplinary issues, and high rates of student failure, dropouts, and the like. However, the researcher argues that without empow- 
erment, teachers should not be blamed for the educational problems persisting in schools today.

With the introduction of new curriculum, challenges have increased in Eritrean educational system and it also become clear that teachers' roles have not been changed over the last few decades. With the changes of the curriculum from teacher centered to student centered approach, the policy in the educational system should also support leadership by teachers. In South Africa, for instance, the Department of Education endorses participative, democratic management and collaboration as open system of learning and site-based management ${ }^{5}$. This helps teachers to fully engage, assume leadership roles and become leaders of their schools.

Although teacher leadership as a concept has been around for quite some time, the reality of the functions and roles that teacher as leaders play in school effectiveness has evolved significantly in the past ten to fifteen years. Teacher leadership was closely associated with role-based theories and models of individual work and job enhancement $\frac{6-8}{}$. Since the mid-1990's, however, teacher leadership has been shifting away from individual empowerment and role-based forms towards more collective, task oriented, and organizational approaches, ${ }^{9,10}$.

In the modern educational system, teacher leadership is an established feature of a school culture and it is behind school effectiveness because it enhances the welfare and morale of teachers. Research has shown that teacher leadership is one of the many factors that can attract and boost teacher's spirit, and help retain talented teachers. In addition, it provides opportunities for teachers to act autonomously and get highly involved in daily school activities. In this study, the researchers attempted to explore that, teachers as leaders of their schools and communities, will then be able to use methods such as those described above to bring positive and long-lasting changes in the workplace.

Some researchers define teacher leadership as a model where teachers at various levels within a school have the opportunity to lead and develop confidence to lead their schools ${ }^{48}$ while some researchers define it as an opportunity for teachers to pursue excellence in the practice of teaching and learning ${ }^{11,12}$. The notion of teacher leadership endorses the function of many instead of a single person's role to enhance school effectiveness and promote collaborative and dynamic teaching profession and increased teacher morale and welfare. In the $21^{\text {st }}$ century, education researchers especially in leadership show the importance of teachers as leaders to build leadership capacity and promote academic excellence. For instance, a study ${ }^{13}$ has shown significant link between school leadership and student achievement. True school leadership remains at the center of focus for effectiveness and academic excellence. Several researchers have discovered that effective school leaders are behind successful schools and they highlight the importance of leadership shifting from authoritarian to distributive as a strategy to produce competent and effective leaders who can directly or indirectly influence schools to flourish and progress powerfully.

The very nature of teacher leadership is embedded within teachers' empowerment through distributed leadership theory. Distributed leadership theory ensures the involvement and participation of teachers in a school leadership capacity regardless of their specific posts. Teacher leadership accounts for wide-spread participation, sharing, collaboration, and cooperation. Moreover, teachers' participation in a school enhances leadership building capacity for the wider community. This includes 
the broad-based and skillful involvement of many people such as teachers, parents, pupils, community members, personnel, and even universities in the work of leadership ${ }^{14}$.

The relationship between teacher leadership and distributed leadership theory has not been explored in-depth, but there is a strong resonance between the empirical terrain provided in teacher leadership literature and the theoretical perspective provided by those writing about distributed forms of leadership $\frac{15-17}{}$. It is clear that emphasis upon collective action, empowerment, and shared agency is reflected in distributed leadership theory. Teacher leadership is centrally and exclusively concerned with the idea that all organizational members can lead and that leadership is a form of agency that should be distributed or shared ${ }^{18}$. Every stakeholder within a school, in one way or another, can demonstrate leadership ${ }^{19}$. This unlocks several opportunities for more teachers to participate and exercise leadership functions. Similarly, high leadership density promotes a larger number of people to be involved in the work of others and to be trusted with information, decision making, as well as to be exposed to new ideas on the creation and transfer of knowledge ${ }^{20}$.

In schools, as elsewhere, we need strong leadership that encompasses an inclusive concept where teachers can participate, share, collaborate and communicate in the structural school leadership as well as in creating a new model of leadership. Teacher leadership is symbiotic in nature, where one entity cannot function without the coexistence of the other. In other words, teacher leadership can only be achieved through the efforts of many within the school and a harmonious leadership structure. Indeed, teacher leadership is a byproduct of a cooperative and inclusive school culture. Nowadays, more than ever,
Eritrean teachers feel excluded from central roles such as leadership, curriculum development, communication, promotion, etc.

\section{Methodology and Data Source}

The study is conducted in two secondary schools and relies on qualitative data to describe the nature of teacher leadership. The role of researchers in qualitative study is very critical and considered as an instrument of data collection ${ }^{21}$. The researchers employed an open-ended questionnaire and a focus group discussion to gather data, and thereby explore the condition, nature, and importance of teacher leadership. In doing so, the researchers selected 97 teachers randomly from a total of 150 teachers to complete open-ended questionnaires.

From those 97 teachers, 20 were selected purposely to engage in a focus group discussion. Then they were divided into two equal groups alphabetically so that every participant could get the chance to share opinions. Hence, the discussion was structured and planned around six predetermined research questions, and each group has given one hour each to share ideas and opinions. The prime goal of the focused group discussion is to generate as many ideas and opinions from teachers. The researchers believed that focused group discussion could disclose a wealth of information and deep insight. Focused group discussion elicits information 22 and it helps also to explore and generate hypotheses ${ }^{\underline{23}}$. In the focused group discussion, the role of the researchers was to explain the purpose of the group discussion, set a comfortable and engaging environment, nurture disclosure in spontaneous manner, facilitate interactions among groups, helping participants feel at ease, and answer their opinions thoughtfully. 


\section{Results and Discussion}

Table 1 shows the teachers' profiles in regards to gender, qualifications, salary, and teaching and leadership experience. None of the participants has ever reached the position of principal, but a few of them have been department heads. The responses from both the focused group discussion and questionnaires supplement each other and enrich significantly the report. This shows that there is reliability in the findings.

During the study, most of the teachers' experience lies within the range of one to five years. The number of teachers decreased with the increase of teaching experience except for those who had taught from 25 to 30 years. A possible cause for this decreased number of teachers is the changing of careers for a more satisfactory salary as many teachers were earning a salary ranging between USD 50-100 per month. There is also the possibility of dissatisfaction resulting from political situations between Western countries and the prolonged-war situation between Eritrea and Ethiopia since 1998.

In the focus group discussion it was stated that every year the schools hire several new teachers from different colleges through the central district office, but at the end of the day many of them disappear. According to the focus group, there are a number of causes for poor teacher retention: poor school leadership, unlimited national service without salary, overloaded teaching staff, absence of teacher input into curriculum development, inadequacy of staff development programs, as well as a lack of promotion, recognition and support from the communities. However, in the focus group, the participants put a great deal of emphasis on salary, and stated that salary is the highest barrier to teacher dissatisfaction. According to the study $63 \%$ of participants fall within a monthly salary of $\$ 50$, and thus teachers seek part time jobs outside of

Table 1. Teachers' profile

\begin{tabular}{|c|c|}
\hline Gender & Male $=73$ \\
& Female $=24$ \\
\hline Qualification & Diploma $=10$, B.A $/$ B.SC $=87$, MA/MSC $=0$ \\
\hline & $1-5=47$ \\
Teaching experience in years & $5-10=23$ \\
& $10-15=7$ \\
& $20-20=6$ \\
& $25-30=9$ \\
\hline Leadership experience & As Department head $=8$ \\
& Principal $=0$ \\
\hline Salary per month & $50-100 \$$ \\
\hline
\end{tabular}


their schools to alleviate the poor living conditions contributed with meager salaries.

The study discovered that teachers' welfare and morale are very poor, and as a consequence of this, teachers do not assume leadership responsibilities and authorities. One unique teacher reported, 'I thought teaching is all about chalk and talk, but finally I have realized that it is far beyond it to include research and leadership roles. I think teacher leadership entails the influence of teachers on school culture, organizational structure, and climate.' If that is the case, then it is the role of schools to create an environment conducive for teachers to exercise and influence their instructional leadership.

\section{Teachers on the Ground Level}

Teacher leadership on the ground level needs the establishment of solid policy that vividly portrays and acknowledges teachers as leaders of their schools. The focus group emphasized the importance of policy as a blueprint for teachers to exercise leadership roles in teaching and learning, as well as in developing self and others. The participants reported that there is no model of leadership that teachers can learn on in Eritrea and, by which, feel able to participate in important school decisions. In effect, teachers are confined to their classroom walls. However, several countries use leadership models as a base for teachers to participate in curriculum and professional development that, in turn, helps them cultivate leadership competencies and teaching skills. For instance, in Australia teachers are responsible for teams or curriculum areas; in New Zealand teachers are curriculum leaders; in Korea chief teachers handle mid-level supervisory duties; while in Spain teachers with reduced workload assume the role of leadership assistants $\underline{24}$.
The sample schools in Eritrea do not have such policies or written roles that consider teachers as leaders in capacity beyond their formal position. The participants define their roles as something that begins and ends in the classroom. However, with introduction of the new curriculum, the role of teachers in Eritrean schools is expected to expand towards the communities. Teachers as leaders go beyond the walls of classrooms and schools towards communities. For instance, in some Finnish municipalities, teachers spend one-third of their work

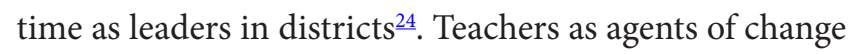
are movers and shakers of school culture. Their leadership potential to develop an inclusive school culture and build leadership capacity is enormous and non-stop force to meet global changes in the pace of advancement. For instance, the participants in the study underlined that the real force for change lies within teachers as leaders.

In Eritrea, as the study reveals, the ground level is not yet prepared or well-organized to treat teachers as leaders. The participants reported that teachers are primarily limited merely to the role of information transmission without participating in curriculum development and roles of greater responsibility outside of the classroom. The main path to teacher leadership is through participation, collaboration and the expanding of one's role towards a school's overall objectives, all of which are concepts embedded in the theory of distributed leadership, meaning leadership roles can be stretched out to many individuals at different levels of a school ${ }^{11,12}$. Through the survey and focus group discussion it was discovered that the policy at the ground level does not support distributed leadership, meaning the schools are not yet well-grounded or well-structured to support teachers as leaders. 
In Eritrea, particularly on the issue of leadership, democracy is sidelined and beleaguered by bosses. The participants reported that teachers have been the victims of imposed curriculum, missions, and goals both from the Ministry of Education and schools' administrations. One participant reported that teachers are silenced, sidelined, and invisible beyond classrooms. This statement was supported by the rest of the focus group when they indicated that the practices within the schools are most often formed from a top-down approach rather than a cooperative approach. In Eritrea the notion of teacher leadership is implicit and yet there is no official document as a policy to promote teachers as leaders of their schools. Teachers are mainly suspended between classrooms and their homes without involvement in larger school matters, such as decision making, strategic planning, delegation, etc. One participant reported, "I feel as if I am excluded from the main culture of the school. I have never been part of the school programs or plans; most of my time is consumed in teaching. I spend my time thinking about how to find extra jobs and make sure I have adequate income to support my family." Teachers are the first stakeholders to encounter educational dilemmas, and thus it is imperative for schools to equip them with leadership skills and also open the door to venture beyond classroom walls.

Building leadership capacity and eliciting efforts from teachers requires an educational community with a friendly atmosphere, instructional collaboration, and strong foundational policy. At the heart of a collaborative and open community, there is a decentralized decision making process whereby teachers become the prime advocates of change throughout a school. Teacher leadership provides operational images of conjoint agency in action and illustrates how distributed forms of leadership can be developed and enhanced in school development and improvement $t^{18}$.

In its simplest form, teacher leadership is all about a decentralized system of leadership. Several scholars claim that a policy shift towards a more democratic and participatory system at all levels of a school opens up room for teacher leadership ${ }^{11}$. In another fashion, some scholars have advocated that teacher leadership can be used as a method to democratize schools $\frac{25}{}$, and to increase community participation $\frac{12}{2}$. In other words, participation and collaboration in school matters would help teachers to think and act as leaders, but without a policy of democracy in the workplace that embraces strong school leadership and qualified teachers, collaboration in leadership roles is inconceivable. One way or another, this implies that teacher leadership should be deep rooted in the policies established at the heart of the learning community.

\section{Teacher Leadership at a School Level}

In the study, the participants imply that the nature and scope of teacher leadership is not yet fully understood and supported both in policy and in practice. This agrees with the fact that in Eritrea, from the policies set forth by the Ministry of Education to the principals in charge, from the teachers to the students, the current system of education is not aligned with the practice of distributed leadership. In support of this statement, the participants' questionnaires indicate that teachers have no control over their profession, structure, and the teaching-learning process as a whole. A study ${ }^{11}$ reveals that teachers were seldom fully involve in school-wide-decision-making, but highly involved in setting of standards about students' 
behavior. However, in the Eritrean sample schools none of the teachers even participate in setting standards about students' discipline. Lack of teacher autonomy to exercise their professional roles in teaching and leadership negatively affects their productivity and commitment to the workplace, and therefore ultimately reduces teachers' capacity to expand and act as leaders of their schools. Both the questionnaires and group discussion explained that teachers come to the job market only with the idea of teaching without considering the vast roles a particular teacher should play in administration, management, and leadership. The participants further reported that once recruited into the pipeline of the entire system, teachers often find that teaching alone is not enough to promote academic excellence and improve school effectiveness without getting involved in leadership roles. In this case, continuous professional development is of paramount importance to bring teachers to the frontlines well equipped with the necessary instructional leadership skills. Moreover a study ${ }^{3}$ discovered that teachers often felt a sense of isolation. In accordance with this, one participant reported, "I am exhausted, marginalized, isolated and walk alone in a narrow world." Teachers have little voice in the workplace especially when it comes to the selection of teaching materials, decision making, and allocation of instructional resources, scheduling classes, and tests for instruction evaluation.

As the study indicates, teacher leadership in Eritrea is not yet fully utilized or developed to the extent where teachers can act as leaders of their schools. The main problems that have plagued the Eritrean education system in regard to teacher leadership are resistance to change, poor school leadership, limited community participation, and the absence of education programs in universities.
The participants in the study further reported that the current educational system is characterized by a lack of participation in curriculum development (imposed curriculum without teacher participation in its creation), authoritative leadership, poor teacher welfare and low morale, top-down communication, lack of community involvement, poor pre-service and in-service training at universities, and a lack of staff development programs in schools. In line with this, the focus group highlighted the absence of a leadership model to rehabilitate and revolutionize the education system.

When power is distributed, each individual is equally invested in a school's performance. A leadership model based on the theory of distributed leadership would work to first give teachers responsibilities outside the classroom, thereby clearly defining their roles as potential instigators of change. Research indicates that teachers as a leaders need to be involved in the provision of curriculum knowledge, management in-service training, provision of assistance to other educators and to participate in performance evaluation ${ }^{11}$. In line with this, some scholars also state that teachers should be offered professional development experience that is both formal and informal, which will subsequently enable individuals to move into leadership roles ${ }^{26}$. Teacher leadership as a distributed ingredient mobilizes teachers to think, believe and act as leaders.

In several studies, it has become clear that teachers spend most of their time in the teaching-learning process without assuming leadership positions until principals themselves share leadership roles. In support of this statement another study ${ }^{27}$ states that non-participatory culture de-motivates teachers and inhibits them from taking leadership initiatives in their schools. Most of the participants (87\%) in the study agree that teacher leadership plays a 
significant role to inspire teachers and improve drastically their welfare and morale, but that principals do not fully recognize and utilize the collaborative potential of teachers. To utilize teachers as leaders of their schools, school management is very important. However, in the study, the participants revealed that principals merely impose tasks on teachers without creating a sense of common purpose that can lead towards teacher empowerment. Yet another study ${ }^{28}$ states that principals are unwilling to redistribute power to teachers for a simple fear that the task may not be adequately performed. Power remains at the office level and teachers are not inspired to take initiative and work innovatively. Perhaps this is one of the many reasons why teachers often times wait for directives to follow and do not look to take the initiative to lead. The participants in the group discussion explained that the teacher-principal relationship is one of servant-master. Surely, this kind of relationship has a detrimental impact on the input from teachers towards building leadership capacity and drastically shrinks the participation of stakeholders in expanding their horizons. In the focus group discussion, the participants explained that there is a myth that leadership belongs to principals, and principals consider leadership as a role of one person rather than a function of all staff. This wrong belief creates distance between principals and teachers. It negatively impacts the principal's rapport among teachers and impedes the creation of an atmosphere of democratic communication and collaborative work ethic.

In a Master's dissertation study ${ }^{29}$ the researcher states that principals need to play pivotal role in developing a school culture and creating a context, which is more comfortable for the practice of teacher leadership. Moreover, she argues that a conducive environment must be cre- ated where teachers can be nurtured and meet the ever changing educational system and keep abreast with the dynamism of change. By the virtue of their positional power ${ }^{11}$ and statutory delegated authority ${ }^{30}$, it can be argued that principals are ultimately responsible for the promotion of teacher leadership through creating a participatory culture and comfortable school context. The implicit idea here is that principals are leaders of leaders ${ }^{31}$. Principals as leaders of leaders have the power to open up an atmosphere of leadership space and continuous professional development for teachers, but most importantly they need to construct the interaction between leaders, followers, and their situations ${ }^{17}$. Some researches even show that when teachers start to lead, the principals' leadership capacity itself expands $\mathrm{s}^{2-34}$.

Successful teacher alignment with the standards, expectations, goals, performance, and progress requires the role of leadership, and supportive and collaborative environment $\frac{35,36}{3}$. In some countries like Denmark, Finland, Norway and Sweden there is long history of teamwork and cooperation among teachers ${ }^{24}$. This helps teachers to play informal leadership roles through sharing ideas, information, and resources among themselves. While in Eritrean, the focused group discussion, states teachers are the victims of poor school outcome, such as students' failure, high dropout rate, and poor curriculum implementation. The participants in the study agreed that school performance is not only the outcome of teaching, but also attributed to leadership by teachers. Some participants also reported that teachers should take full responsibility to partake in leadership roles without waiting for the green light from principals to get involved. Whatever the case may be, teachers need to assume leadership position, if teaching is to be accepted as a pro- 
fession ${ }^{37}$. In the study, it has become clear that teachers who do not assume leadership positions are confined to the classroom.

From the findings, it is evident that teachers irrespective of their age, experience, or qualifications support the notion of teacher leadership and believe that they have potential to be leaders, but the degree of involvement in leadership roles, responsibilities and/or authority is very low. The majority of teachers view their professional practice only within the classrooms, thinking that it will be enough to improve instructional practices. Thus they do not provide curriculum development knowledge and participate in school-wide decision making. A Study ${ }^{\frac{38}{6}}$ refers to this situation as a restricted form of teacher leadership. Given this information, it can also be said that the Eritrean education system does not support a fully democratic policy. Researchers in the field confirm that teacher leadership in practice is chiefly restricted to classrooms, and attribute this restriction to the school culture and the principal's individual role as leader of leaders ${ }^{11}$. This implies that teacher leadership relies on the context in a school and teachers' involvement beyond classrooms. However, research shows that in every school teachers as leaders have numerous opportunities to extend their roles beyond classrooms towards the school as a whole and far beyond the school, even to the district level ${ }^{39}$.

Historically, there has been a belief that a good teacher always stays in a classroom, shows punctuality, and loyalty to his or her supervisors. Teachers have been conditioned to teach and to submit to authorities without questioning their own potential leadership qualities. As a consequence of this, the teachers' primary function is seen as teaching students and obeying rules from the authorities above, and thus most of their time and energy is spent dealing with classrooms tasks with little time left over to assume leadership roles. Researches argue that teachers need to possess both formal and informal leadership roles. Studies $\frac{31,40}{10}$ have made the distinction between the two terms 'formal' and 'informal'. Informal leadership comprises classroom related functions, such as planning, communicating goals, creating a pleasant workplace, regulating activities, supervising, motivating, and evaluating performances; whereas formal leadership is comprised of positions such as subject coordinator or head of department. Teachers as leaders have more opportunities for responsibility beyond classrooms, such as team leaders, curriculum developers, department chairs, and association leaders to name a few ${ }^{41}$.

In education, as in other fields, we need the participation and collaboration of teachers to promote a culture of collective effort, to build trust, and to create a sense of belonging and ownership. Teachers are leaders of their schools and agents of change, and thus leadership should be shared in order to influence school culture and impact school improvement positively. Teachers without high-caliber qualifications and understanding of their inherent leadership roles, however, are helpless and remain restricted in classrooms. Yet another study $y^{42}$ claims that teachers are leaders of their schools when they start to function in professional learning communities, participate in educational improvement, and inspire excellence in practice. In line with this ${ }^{11}$, states that the central concept of teacher leadership is the notion that teachers continually endeavor to promote their teaching. Hence, a new kind of organizational structure, change, and model of participative leadership may be helpful for teachers to function as leaders of their schools and shape learning culture. Teachers who lead and function as lead- 
ers help shape their school culture and their own destinies as educators ${ }^{32}$. In accordance with this, $\mathrm{a}^{43}$ states that teacher leaders can play a crucial role in shaping school culture, programs, and policies.

From the findings, it can be seen that teachers in Eritrea lack personal awareness and interpersonal relationships in regards to their leadership functions. Some research shows that teachers as leaders grow their understanding about various roles as they lead instructional, organizational, and professional practices ${ }^{\underline{44}}$. Moreover, teachers' attitude, confidence, and beliefs have a powerful impact on teacher leadership. Based on the literature review and implied findings, it can be argued that those who acquire personal and interpersonal management skills are very influential in changing school culture and have a powerful impact as they become leaders of their schools. The role of school leaders, however, serves as a base for teachers to realize and utilize their leadership potential. Researchers suggest that entrusting teachers through teacher leadership improves their self-efficacy ${ }^{26}$ and releases the talent and energy of teachers towards self-actualization ${ }^{45}$. Only when principals are determined to establish a promotional context, caring environment, open communication, and collaborative culture can teachers start to kindle their leadership awareness. Unfortunately, until now many teachers in Eritrea have been in a professional context where the authoritative power of principals is more intimidating than caring, and less open to collaborating, promoting, and creating opportunities for teacher leadership opportunities.

In the focus group discussion, the participants asserted that teacher leadership could be enhanced by building confidence, coaching, modeling leadership, team work, conferences, workshops, action research, col- laboration, and more access to information and resources. Researches also suggest that school cultural conditions, such as school-wide practices, teamwork, sharing of responsibility, decision-making and teacher communities facilitate teacher leadership ${ }^{44}$. School cultural conditions require principals' understanding that leadership is a function of all teachers. The principals in the sample schools, however, were trained as teachers, not as leaders. Hence, it is hard for principals to model, mentor, and coach teachers as their strategies are more managerial in nature rather than inspirational and encouraging. One participant reported, "Principals have two assignments. One is to check teacher attendance and the second is to command teachers". Moreover, the participant adds that although principals have good hearts to promote teacher leadership, they lack the necessary leadership skills to do so; principals were poor teachers like me, but now they occupy a position of leadership which requires the skills and expertise to model teacher leadership. Therefore, if the problem is about leadership skills, principals in Eritrea need to shift the current policy from a centralized educational system to a decentralized policy. Principals themselves must learn how to promote teacher leadership by distributing responsibility and power, sharing decision making authority, allowing the formation staff committees, considering staff opinions, promoting effective group problem solving, providing autonomy, altering working conditions, ensuring adequate involvement of all staff, and creating opportunities for staff development ${ }^{2}$.

\section{Results}

It is a well-known fact that teacher leadership evolves from a new understanding of organizational development and the need for active involvement of individuals at all 
levels within the domain of an organization. Educational improvement and effectiveness is not only a matter of subject mastery, but an issue of teacher leadership. Teacher leadership expands to include roles ranging from classroom tasks to school management to evaluating educational initiatives and facilitating professional learning communities. With the continuously expanding roles of teachers, teaching and learning improves and results in increased student achievement ${ }^{\frac{44}{4}}$. In conclusion, teacher leadership is an important practice for improving quality education, boosting teachers' confidence, expertise and lifelong learning, unlocking the individual and collective potentials of teachers, ensuring educational change, innovation, and reform, as well as promoting high student learning and achievement, producing an excellent and fun learning environment, and increasing teacher recruitment and retention. From the study it can be further deduced that teacher leadership in the Eritrean educational system has not yet been activated as a policy. In order to bring into existence, first the efficient practice of school management should embrace a bottom-up influence to replace the current linear decision-making process. Then, through innovative approaches, teachers need to be prepared, resourced, trained, coached, counseled, mentored, and developed as leaders to address leadership roles, responsibilities, or powers with the aim of bringing academic excellence into students' lives. Such practices will naturally create a situation where teachers can assume leadership positions and create a network of collaboration among themselves and within their communities. Strong teacher leadership is an inclusive outcome of all interrelated factors within a school. Another study ${ }^{46}$ maintains that strong, consistent, principled and inspired leadership as essential ingredients of good school. For instance, scratch down the surface of successful school, and then you will find a powerful and democratic leadership, and scratch also the surface of unsuccessful school, definitely you will find the reverse. This is the conventional wisdom where everyone agrees upon.

\section{Policy Implications for Development}

Generally, leadership in educational settings needs greater skills, trust, confidence, empathy and visibility, which is something that strong school leadership can facilitate. In other words, it needs a clear and shared vision from which teachers can lead and function as leaders of their schools. Future teachers in the profession will need to emphasize working beyond classroom zones and to develop a number of social competencies. As teachers take time and the assistance to cultivate their leadership potential, schools, communities, and the Ministry of Education need to create a space for teacher leadership to develop and become part of the educational system. Educational leaders and policy makers need to allow enough time for teachers to learn, grow, change, and practice leadership skills in the classroom, school, and beyond. At this juncture, teachers especially need the preparation and training in order to develop their leadership capacity and management processes. Teachers need assistance from principals to understand the nature of their leadership responsibilities and apply the changes in their practices to meet challenges. There is also a need for teachers to understand and assume leadership positions with better understanding and more preparation. Based on the study, the researcher has come up with the following three specific recommendations. 
Teachers are leaders of their schools when teacher leadership becomes part of a school culture. Teacher leadership is a strategy to expand and maximize teachers' potential and capacities within the arena of the learning community and helps to build sustainable academic excellence. In Eritrea, however, teachers are confined within the classroom world, and the link between teacher leadership and school effectiveness has not yet been established. Therefore, teachers should assume their leadership responsibilities and take an active role in educational and cultural restructuring. Moreover, they should realize that the essence of teacher leadership is all about participation, learning together, collaboration, and the sharing of educational goals.

Teachers in Eritrea as elsewhere occupy the largest portion of the personnel within schools, and thus teacher leadership need to have the context of understanding and full support from educators, leaders, parents, communities and the ministry. It is a well-known fact that teacher leadership has a tremendous impact on school improvement and effectiveness, if entrusted with leadership authority. Teacher leadership surely but slowly helps to build leadership capacity. Some researchers reported that teacher leadership continually improves not only the teaching and learning, but also develops the expert power and reinforces the idea that teachers could and should lead ${ }^{11}$. Educational improvement and high-caliber leadership is a byproduct of an inclusive school culture and visionary leadership. The core values and norms that underlie a school's culture and practices determine school organization, structure, policies, programs, and plans. Leadership is not a position or a title, but a choice to serve the clients and teach the masses by learning together, creating meaning, and working collaboratively for a common purpose in accordance with the foundational principles and policies. However, this requires a structural or organizational change with an emphasis on capturing the gifts, talents, abilities and skills of all citizens through a democratic and educated community. It is the hope of the researcher that the Ministry of Education will set up an inclusive policy of leadership that clearly shows the big picture and common mission so as to help teachers step out from behind the classroom walls and into the greater school environment and community.

\section{References}

1. Andrew MD. Teacher leadership: A model for change (Bulletin 37). Washington, DC: Association of Teacher Educators; 1974. p. 5.

2. Southworth G. Think Piece from NCSL. Times Educational Supplement; 2002.

3. Little JW. Contested ground: The basis of teacher leadership in two restructuring higher schools. The Elementary School Journal. 1995; 96(1):47-63. Crossref.

4. Little JW. Assessing the prospects for teacher leadership. The Jossey-Bass Reader on Educational Leadership. San Franscisco, CA: Jossey-Bass; 2000.

5. Van der Mescht H. Educational leadership and management - some thoughts from the field. Journal of Education. 2008; 44:7-14.

6. Hart A. Reconceiving school leadership: emergent views. The Elementary School Journal. 1995; 96:9-28. Crossref.

7. Hart AW. Work resign: A review of literature for education reform. 1(31-69). Greenwich, CT: JAI Press; 1990.

8. Pounder DG. Teacher teams: Exploring job characteristics and work related outcomes of workgroup enhancement. Educational Administration Quarterly. 1999; 35:317-348. Crossref.

9. Leithwood, Jantzi D. Distributed leadership and student engagement in school. Annual Meeting of the American Educational Research Association; San Diego, CA. 1998.

10. Leithwood K, Jantzi D. The effect of different sources of leadership on student engagement in school: Leadership for change and school reform. New York: Routledge/Falmer; 2000. p. 50-66.

11. Grant C, Gardner K, Kajee F, Moodley R, Somaroo S. Teacher leadership: a survey analysis of KwaZulu-Natal 
teachers' perception. South African Journal of Education. 2010; 30:401-19.

12. Grant C. Teacher leadership: some South African voices. Education management, administration and leadership. 2006; 34:511-32. Crossref.

13. Wallas Foundation. The school principal as leader: Guiding schools to better teaching and learning. New York; 2011.

14. Lambert L. Building leadership capacity in schools. Alaxandria, VA: Association for Supervision and Curriculum Development; 1998.

15. Gronn P. Distributed properties: A new architecture for leadership. Educational and Administration. 2000; 28(3):317-38. Crossref.

16. Spillane J. Investigating school leadership practice: A distributed perspective. Educational Research. 2001; 30(3):23-8. Crossref.

17. Spillane J. Distributed leadership. San Francisco: JosseyBass; 2006. PMCid:PMC2598602

18. Harris A. Teacher leadership as distributed leadership: Heresy, fantasy or possibility? School Leadership and Management. 2003; 23(3):313-24. Crossref.

19. Goleman D. Leadership that gets results. Harvard Business Review; 2000 Mar-Apr.

20. Sergiovanni T. Leadership: what's in it for schools? London: Routledge Falmer; 2001.

21. Denzin NK, Lincoln Y, editors. The language of qualitative research: Theories and issues. 2nd ed. London: Sage; 2003. PMCid:PMC171390

22. Morgan DL. Focus groups as qualitative research. London: Sage; 1988.

23. Powell RA, Single HM, Lloyd KR. Focus groups in mental health research: Enhancing the validity of user and provider questionnaires. International Journal of Social Psychology. 1996; 42(3):193-206. Crossref. PMid:8889643

24. Schleicher A, editor. Preparing teachers and developing school leaders for the 21st century: Lessons from around the World. OECD Publishing; 2012.

25. Gunter H. Leading teachers. London: Continuum; 2005.

26. Katzenmeyer M, Moller G. Awakening the sleeping giant: Helping teachers develop as leaders. Thousand Oaks, CA: Corwin Press, Inc; 2001.

27. Ntuzela M. The role of the school management team in developing teacher leadership: case studies of two public primary schools on the lower South Coast of KwaZuluNatal. Unpublished MEd dissertation. Pietermaritzburg: University of KwaZulu-Natal; 2008.
28. MacBeath J. Leadership as distributed: A matter of practice. School Leadership and Management. 2005; 25:349-66. Crossref.

29. Pillay S. Teacher leadership: A self-study. Unpublished MEd dissertation. Pietermaritzburg: University of KwaZuluNatal; 2008.

30. Mbatha L, Grobler B, Loock C. Delegation of authority by school principals: An education law perspective. Education as Change. 2006; 10:3-15. Crossref.

31. Ash RC, Persall JM. The principal as chief learning officer: Developing teacher leaders. NASSP Bulletin. 2000; 84(616):15-22. Crossref.

32. Barth RS. Teacher leader. Phi Delta Kappan. 2001; 82(6):4439. Crossref.

33. Barth R. Improving schools from within: Teachers, parents and principals can make a difference. San Francisco: Jossey-Bass; 1990.

34. Barth RS. The Teacher Leader. Providence: The Rhode Island Foundation; 1999.

35. Lieberman A, Saxl E, Miles M. Building a professional culture in new schools. New York: Teachers' College Press; 1988.

36. Lieberman A, et al. Teacher leadership: Ideology and practice. Jossey-Bass Reader on Educational Leadership. Chicago: Jossey-Bass; 2000.

37. Hinchey P. Teacher leadership: Introduction. The Clearing House. 1997; 70(5):233. Crossref.

38. Harris A, Muijs D. Improving schools through teacher leadership. Maidenhead: Open University Press; 2005.

39. Danielson C. The many faces of leadership. Educational Leadership. 2007; 65(1). Available from: http://tinyurl. com/2q8edz

40. Gehrke N. Development Teacher Leadership Skills. ERIC Digest; 1991.

41. Boyd V, McGree K. Leading change from the classroom: Teachers as leaders. Issues...About Change. 1995; 4(4). Available from: http://www.sedl.org/change/issues/ issues 44. html

42. Childs-Bowen D, Moller G, Scrivner J. Principals: Leaders of leaders. National Association of Secondary School Principals (NASSP) Bulletin. 2000; 84(616):27-34. Crossref.

43. Danielson C. Chapter 5: School-wide policies and programs. Danielson C, editor. Teacher leadership that strengthens professional practice. Alexandria, VA: Association for Supervision and Curriculum Development; 2006. Available from: http://www.ascd.org/portal/site/ascd/template.chapter/menuitem.5d91564f4fe4548cdeb3ffdb62108a0c/?chapt 
erMgmtId=0c11876d39b29010VgnVCM1000003d01a8c0 RCRD

44. York-Barr J, Duke K. What do we know about teacher leadership? Findings from two decades of scholarship. Review of Educational Research, 2004; 74(3):255-316. Crossref.

45. Covey S. The four roles of leadership. New York: Franklin Covey co; 1999.
46. Lightfoot S. The good high school: portraits of character and culture. United States: Basic Books; 1983.

47. Fullan M. Leading in a Culture of Change. San Franscisco: Jossey Bass; 2001.

48. Harris A, Lambert L. Building leadership capacity for school improvement. Buckingham: Open University Press; 2003. 